\title{
Benefícios e Problemas nas Relações de Fornecimento Enxuto: Indicações na Indústria Automobilística Brasileira
}

\author{
Rebecca Arkader
}

\section{RESUMO}

Este trabalho baseia-se nos resultados de pesquisa de estudo de casos em montadoras e fornecedores na indústria automobilística brasileira, para verificar as percepções de benefícios e problemas decorrentes dos novos padrões de relações de fornecimento a partir da adoção de práticas da produção enxuta. Os benefícios e problemas percebidos pelas 12 empresas entrevistadas, 3 montadoras e 9 fornecedores, são apresentados e discutidos à luz daqueles registrados na literatura. Os resultados apontam para uma convergência com as percepções levantadas em pesquisas na mesma indústria em outros países, com diferenças que indicam uma atitude estratégica e positiva dos fornecedores brasileiros em face das maiores exigências impostas pelas práticas de fornecimento enxuto.

Palavras-chaves: relacionamento entre compradores e fornecedores; indústria automobilística brasileira; benefícios no relacionamento; problemas no relacionamento.

\begin{abstract}
This paper draws on results from case study research with car assemblers and autoparts suppliers in the Brazilian automotive industry in order to investigate the perception on benefits and problems arising from new patterns of buyer-supplier relationships brought by the adoption of lean production practices in manufacturing. The benefits and problems as perceived by the 12 interviewed companies, three assemblers and 9 suppliers, are presented and discussed in view of benefits and problems mentioned in the literature. The results point to a convergence in the perceptions found by research on the matter undertaken in the same industry in other countries, with differences indicative of a strategic and positive attitude on the part of Brazilian suppliers in face of our more demanding conditions dictated by lean supply practices adopted by their clients.
\end{abstract}

Key words: buyer-supplier relationship; brazilian automotive industry; benefits in the relationship; problems in the relationship. 


\section{INTRODUÇÃO}

As relações entre compradores e fornecedores na indústria automobilística ocidental têm sofrido notável mudança nos últimos anos, inspirada pelas lições trazidas pelos estudos das práticas japonesas cujo conjunto veio a ser conhecido como produção enxuta. Durante todo o decorrer da década de 80 , os aspectos operacionais do Sistema Toyota de Produção, ou seja, da filosofia e do conjunto de técnicas de gestão da produção correspondentes ao sistema just-in-time (JIT) foram promovidos por diversos especialistas ocidentais, que destacaram suas vantagens em termos de eficiência, qualidade e flexibilidade.

O estímulo mais importante à adoção do novo sistema na indústria automobilística, porém, teve origem na iniciativa do International Motor Vehicle Program (IMVP), coordenado pelo MIT, cujos resultados exerceram grande influência sobre as pesquisas das fontes da vantagem competitiva dos produtores japoneses em face dos americanos e europeus. Através, em especial, do livro The Machine that Changed the World (Womack, Jones e Roos, 1991), ocorreu ampla divulgação das bases tanto da produção quanto do fornecimento enxuto para o atingimento de ganhos competitivos na indústria, em contraposição àquelas da produção em massa.

A indústria automobilística tem sido, com efeito, cenário de boa parte dos estudos das relações de fornecimento em contextos JIT (além de ter sido sua origem). Uma primeira razão para isso parece ser a importância do setor automotor em todas as economias em que está presente: no caso brasileiro, respondeu isoladamente em 1995 por 12,9\% do PIB Industrial. Esta participação cresceria ainda mais se considerado o faturamento gerado pelo setor de autopeças em vendas não destinadas às montadoras, que acrescentaria aproximadamente outros 3,4\% (ANFAVEA, 1996). Contribui também para o grande interesse em se estudarem as relações entre montadoras e fornecedores de autopeças o fato de a produção de automóveis ser uma manufatura complexa, em que intervêm cerca de dez mil componentes, constituindo o que é talvez o bem durável mais caro para seus consumidores.

Diversos estudos apontaram uma tendência cada vez maior na indústria automobilística dos países industrializados na direção da adoção de práticas de produção e fornecimento enxutos (e.g.: Cusumano e Takeishi, 1991; Lamming, 1993; Turnbull et al., 1993; Helper, 1994; Sako, Lamming e Helper, 1995). Parte deste esforço foi dedicado a identificar os benefícios e problemas que o novo tipo de relacionamento - práticas de entrega JIT, novas atitudes em face da qualidade, 
maior responsabilidade dos fornecedores no projeto - acarreta para montadoras e fornecedores. Esta questão é relevante à medida que coloca os incentivos ou desincentivos para que as partes se envolvam nas novas configurações de relacionamento segundo o modelo de fornecimento enxuto.

Até o presente têm sido escassas na literatura as indicações sobre mudanças nos padrões de relacionamento entre montadoras e fornecedores de autopeças em países em desenvolvimento. No Brasil, especificamente, foi apenas a partir da abertura da economia, em 1990, que se iniciaram esforços mais consistentes na direção de adoção de práticas identificadas com o paradigma da produção enxuta. A estabilização da economia e o crescimento da demanda têm constituído estímulos ao seu desenvolvimento nos últimos três anos, fazendo com que comecem a se esboçar entre os atores da indústria percepções sobre as implicações dos novos padrões de relacionamento. Cabe agora, portanto, investigar até que ponto tem havido incentivos ao avanço do fornecimento enxuto no país e, ainda, se as percepções dos participantes na indústria automobilística brasileira coincidem com aquelas registradas em outros países.

Este trabalho apresenta resultados de uma pesquisa sobre as relações de fornecimento na indústria automobilística (Arkader, 1997), em que se constataram avanços na direção da adoção de entregas e outros elementos do sistema JIT, focando especificamente os benefícios e problemas percebidos pelas partes na implementação de práticas de fornecimento enxuto. Após breve revisão da literatura pertinente, apresenta-se a metodologia utilizada para o estudo empírico junto às montadoras de automóveis e a fornecedores de autopeças. Apresentam-se, a seguir, os resultados da pesquisa que, por fim, são discutidos, concluindo-se o trabalho com uma apreciação dos incentivos até o presente ao desenvolvimento de relações de fornecimento segundo o modelo da produção enxuta e do grau de coincidência com as constatações de estudos realizados em outros contextos.

\section{ReVISÃo dA LITERATURA}

A literatura de gerência de operações, logística e compras tem evidenciado o vínculo estreito entre as questões de fornecimento e a operacionalização de sistemas JIT (Schonberger e Gilbert, 1983; O'Neal, 1989; Billesbach, Harrison e Croom-Morgan, 1991; Dion et al., 1992; Fawcett e Birou, 1993; Karlsson e Norr, 1994; Hines, 1994). Percebe-se que o sucesso do JIT depende do desempenho do sistema como um todo, sendo necessária a integração entre as diferentes funções (Spencer, Rogers e Daugherty, 1994). O estabelecimento de uma prática de entregas JIT parece ser o coroamento da implantação de um sistema de manufatura 
just-in-time. Não é por acaso que o evento, datado de 1973, em que a "Toyota permitiu a seus fornecedores entregarem diretamente às linhas de montagem, ligando-os plenamente ao seu sistema interno de aporte de peças" (Cusumano, 1988, p. 35) encerra a cronologia, iniciada em 1948, de desenvolvimento e implantação do Sistema Toyota de Produção, matriz do sistema JIT. De fato, seus benefícios têm sido reconhecidos em estudos conduzidos nos Estados Unidos, Reino Unido e Japão, nos quais inúmeras firmas consideraram a prática como um dos componentes mais importantes no processo de operacionalização de uma produção enxuta (Billesbach, Harrison e Croom-Morgan, 1991).

Destacam-se, portanto, os benefícios advindos de entregas JIT. Schonberger e Gilbert (1983) listaram as vantagens para o comprador e para o vendedor ${ }^{(1)}$ das compras JIT, comparadas no Quadro 1 a seguir.

Os autores ressaltaram que o benefício mais aparente, para os compradores, seria a eliminação dos custos com o estoque alheio. O mais importante, no entanto, seriam a qualidade e produtividade, bem como a relação simbiótica que levaria a outros ganhos mútuos, como os de procedimentos administrativos de compra.

Para os fornecedores, "a felicidade estaria em ter um contrato exclusivo (ou praticamente), de longo prazo e invariável - que são as características de um acordo de compra JIT" (Schonberger e Gilbert, 1983, p. 65). Isso permitiria aos fornecedores beneficiarem-se de capacidade plena, retenção de mão-de-obra treinada e corte de seus próprios estoques.

Para Schonberger e Gilbert (1983, p. 68), mesmo com orientação de curtoprazo, "as compras JIT poderiam ser atraentes para muitas firmas manufatureiras, devido ao fato de que os custos combinados - preço, papelada, manutenção de estoques, transportes, defeitos e assim por diante - podem ser menores mesmo no curto prazo".

Estudo conduzido entre 23 firmas compradoras (OEM) na indústria automotriz americana quanto ao desempenho de determinados aspectos do sistema JIT (O'Neal, 1989) confirmou os benefícios anteriormente citados no fornecimento JIT: redução no número de fontes de fornecimento, aumento na intensidade de interação entre compradores e fornecedores, aumento na freqüência de entregas pelos fornecedores e redução nos estoques de produtos acabados. 


\section{Quadro 1: Vantagens para Compradores e Fornecedores no Fornecimento JIT}

\begin{tabular}{|c|c|}
\hline Compradores & Fornecedores \\
\hline \multicolumn{2}{|l|}{ Custo dos Materiais } \\
\hline $\begin{array}{l}\text { redução no custo dos estoques } \\
\text { redução no custo das peças através de efeitos de curva } \\
\text { de aprendizado a longo prazo com fornecedores limitados } \\
\text { redução nos custos de transporte com fornecedores próximos } \\
\text { redução no custo de sucata devido à detecção precoce de } \\
\text { defeitos }\end{array}$ & $\begin{array}{l}\text { redução no custos com estoques } \\
\text { de produtos acabados e de } \\
\text { produtos em processo } \\
\text { redução nos estoques adquiridos, } \\
\text { se o JIT for usado pelos forne- } \\
\text { cedores da própria firma }\end{array}$ \\
\hline \multicolumn{2}{|l|}{ Eficiência Administrativa } \\
\hline $\begin{array}{l}\text {. exige menor solicitação de propostas } \\
\text { menor número de fornecedores para a celebração de contratos } \\
\text {. contratos negociados com pouca freqüência } \\
\text {. papelada de liberação minimizada } \\
\text {. redução na tarefa de expedição } \\
\text {. redução nas distâncias e custos de viagens e ligações } \\
\text { telefônicas } \\
\text {. estímulo a uma comunicação mais freqüente com o fornecedor } \\
\text { simplificação da contabilidade de peças recebidas caso os } \\
\text { fornecedores usem embalagens padronizadas } \\
\text {. identificação confiável dos pedidos que chegam, caso os } \\
\text { fornecedores usem uma rotulação rigorosa das embalagens }\end{array}$ & $\begin{array}{l}\text {. estimula a comunicação mais } \\
\text { freqüente com o comprador, } \\
\text { evitando assim as confusões } \\
\text {. aumento no controle do estoque } \\
\text { de produtos acabados, em decor- } \\
\text { rência de serem os embarques } \\
\text { firmes e previsíveis } \\
\text {. a firma fornecedora ganha } \\
\text { prestígio aos olhos do compra- } \\
\text { dor JIT, devido à maior resposta } \\
\text { em termos de qualidade e projeto } \\
\text { redução no risco do negócio a } \\
\text { longo prazo }\end{array}$ \\
\hline \multicolumn{2}{|l|}{ Qualidade } \\
\hline $\begin{array}{l}\text { detecção rápida de defeitos, devido às entregas freqüentes } \\
\text {. correção rápida dos defeitos, tendo em vista os set-ups } \\
\text { freqüentes e os pequenos lotes dos fornecedores } \\
\text { menor necessidade de inspeção (dos lotes), em vista do } \\
\text { estímulo ao controle do processo } \\
\text {. alta qualidade das peças adquiridas e dos produtos nos quais } \\
\text { são montadas }\end{array}$ & $\begin{array}{l}\text {. evita a produção de grandes lotes } \\
\text { defeituosos } \\
\text { melhora a coordenação em } \\
\text { assuntos de garantia de qualida- } \\
\text { de }\end{array}$ \\
\hline \multicolumn{2}{|l|}{ Projeto } \\
\hline $\begin{array}{l}\text { resposta rápida a mudanças de engenharia } \\
\text { inovatividade no projeto, tendo em vista que o fornecedor é o } \\
\text { especialista }\end{array}$ & $\begin{array}{l}\text { melhora a coordenação de } \\
\text { problemas relacionados à enge- } \\
\text { nharia }\end{array}$ \\
\hline \multicolumn{2}{|l|}{ Produtividade } \\
\hline $\begin{array}{l}\text { redução nos custos de materiais } \\
\text {. redução no retrabalho } \\
\text {. redução na inspeção } \\
\text {. redução no atraso devido a peças fora de especificação, } \\
\text { entregas atrasadas ou entregas a menor } \\
\text { redução nas atividades nas funções de compras, controle da } \\
\text { produção, controle de estoques e supervisão, com suprimento } \\
\text { mais confiável de peças e manutenção de menores quantida- } \\
\text { des }\end{array}$ & $\begin{array}{l}\text {. aumenta a capacidade de se } \\
\text { prever e compartilhar capacidade } \\
\text { no pico } \\
\text {. ajuda na retenção de uma mão- } \\
\text { de-obra treinada }\end{array}$ \\
\hline
\end{tabular}

Fonte: Schonberger e Gilbert, 1983 
Em pesquisa em diversos setores industriais, em que predominaram empresas dos setores de equipamentos de transporte, eletroeletrônica e máquinas (Fawcett e Birou, 1993) com grau moderado de adoção de compras JIT, os respondentes manifestaram-se quanto aos benefícios relativos a medidas de desempenho relacionadas ou não a custos. Entre estas últimas, as percepções foram de benefícios auferidos em melhorias na programação da produção, posição competitiva total, produtividade, qualidade e resposta dos fornecedores. Entre as medidas relativas a custos, o maior impacto percebido foi quanto à diminuição nos custos com estoques e com custos de retrabalho e sucata.

Os resultados dos estudos citados parecem indicar que, pelo menos do ponto de vista dos compradores, o fornecimento JIT só parece trazer vantagens. Mas há discordâncias na literatura, sobretudo quando se olha o lado dos fornecedores. Haveria muitos fornecedores, alegando que seus clientes tentam transferir a eles seus próprios problemas, sobretudo os estoques. Este ponto-de-vista é levantado por diversos autores (Womack et al., 1991; Delbridge e Oliver, 1991; Helper, 1991, 1994; Lamming, 1993; Turnbull et al., 1993; Karlsson e Norr, 1994; Helper e Sako, 1995).

Karlsson e Norr (1994), a partir de dois estudos de casos conduzidos na Suécia, observaram a existência de riscos de que, nas fases iniciais da transformação para a produção enxuta, ocorresse uma transferência gradual de problemas para trás na cadeia de manufatura. As pesquisas de Helper $(1991,1994)$ ressaltam esse aspecto na indústria automobilística americana. Em suas pesquisas junto a fornecedores de autopeças independentes de primeiro nível, a autora verificou que ainda em 1993 metade considerava que o JIT não fazia mais do que transferir a eles a responsabilidade pelos estoques dos clientes; além disso, constituiria um problema a falta de programações de entrega estáveis por parte das montadoras (Helper, 1994).

Outra questão analisada por Helper $(1991,1994)$ foi a da relação entre entregas e produção JIT. A autora constatou que o tamanho médio dos lotes entregues aos clientes era muito menor do que o tamanho médio dos lotes produzidos pelos fornecedores; embora ao longo de sucessivas pesquisas ambos os tamanhos houvessem diminuído, a redução maior havia sido constatada, em 1993, naquele dos lotes de entrega. Para que se obtivessem maiores benefícios na produção enxuta, a autora apontava a necessidade de que os clientes mantivessem estáveis seus cronogramas de entregas solicitadas pelo menos durante o leadtime dos fornecedores, de tal forma que estes pudessem reduzir seus lotes; caso contrário, a necessidade de manter estoques continuaria fazendo com que incorressem em custos; seria um efeito em cascata: com lotes menores, seu leadtime também seria menor, permitindo a fixação da programação do cliente com menor antecedência. Nesse caso, cliente e fornecedor se beneficiariam de maior rapidez na implementação de 
mudanças de engenharia e na identificação de defeitos, bem como de menores custos de manutenção de estoques (Helper, 1991). Além disso, não se constatava entre os fornecedores americanos reduções de custos, os quais se teriam elevado em quase 1,7\% ao ano em termos nominais entre 1988 e 1992, sendo as reduções de preços praticados para as montadoras devidas antes a uma compressão nas margens (Helper, 1994).

Embora a maior parte dos estudos analise os benefícios e problemas da prática mais evidente do fornecimento enxuto, justamente as entregas JIT, o modelo tem caráter mais amplo, envolvendo também aspectos de colaboração inter-empresas e maior participação dos fornecedores na agregação de valor ao produto final, no que se configura como modelo de parceria entre compradores e fornecedores, em oposição à distância e antagonismo característicos do modelo tradicional (Fleury e Arkader, 1996). A este aspecto estratégico tem sido atribuído o desempenho superior da indústria automobilística japonesa (Nishiguchi, 1989; Sako, 1992; Hines, 1994). Nesta perspectiva mais abrangente, conceitua-se que os relacionamentos deveriam ser um jogo ganha-ganha (Carlysle e Parker, 1989), com benefícios advindos a todas as partes; a realidade parece nem sempre corroborar esse resultado, o qual tem sido questionado, pelo menos em parte, na literatura (Lamming, 1993; Stuart, 1993; Turnbull et al., 1993; Purdy, Astad e Safayerie, 1994).

Lyons, Krachenberg e Henke Jr. (1990) observaram que os compradores enfatizavam as vantagens e raramente mencionavam desvantagens significativas nas novas relações de fornecimento; por outro lado, os fornecedores consultados enfocavam as desvantagens e consideravam as vantagens apenas de forma marginal. Entre as vantagens constatadas pelos compradores estavam:

. a redução no custo de fabricação e de mão-de-obra e melhoria da qualidade;

. a redução na complexidade da montagem e na compra;

. a garantia de fornecimento;

. os relacionamentos cooperativos com fornecedores;

. a previsibilidade nos contratos;

. a garantia de preço justo (transparência nos custos);

. as reduções negociadas de preço durante a vida do contrato.

Entre as desvantagens para os compradores, foram citadas:

. maior dependência do fornecedor;

. a necessidade de novo estilo de negociação;

. menor competição entre fornecedores;

. necessidade de maior capacitação gerencial;

. menor mobilidade de pessoal;

. maiores custos de comunicação e coordenação; 
. maior apoio aos fornecedores;

. novas estruturas de recompensa;

. perda de contatos diretos com fornecedores secundários.

Pelo lado do fornecedor, Lyons, Krachenberg e Henke Jr. (1990) listaram as seguintes vantagens efetivas:

. previsibilidade contratual;

. maior estabilidade de mão-de-obra e produção;

. maior eficácia em P\&D;

. assistência do comprador;

. influência no processo de decisão futuro do comprador;

. informação interna sobre decisões de compra;

. informações sobre a concorrência.

As desvantagens para os fornecedores seriam:

. divulgação de informações de custos (perda de informação proprietária);

- pressões para assumir a carga de todas as fases, do desenho à garantia, ao mesmo tempo que se melhora a qualidade e se reduzem custos;

. perda de autonomia;

. maiores custos de comunicação e coordenação;

. menor mobilidade de pessoal;

. reversão potencial do pêndulo (consciência de que o paradigma de relacionamento pode mudar no futuro, voltando a favorecer a integração vertical).

Leavy (1994, p. 49) resumiu as vantagens para o comprador dos novos relacionamentos: "muitos dos benefícios da integração vertical com poucos de seus riscos". Seria o "nirvana intercorporativo" (New, 1994, p. 61) visto pelo lado do comprador. Os perigos, para as duas partes, estariam em se aliar à firma errada, com os custos e riscos de uma eventual necessidade de troca, e na impossibilidade de crescimento de ambos de forma complementar (Leavy, 1994).

Tais discussões indicariam que para as compradoras, pelo menos em sua percepção, predominariam os benefícios na adoção de práticas de fornecimento enxuto. Para os fornecedores, porém, predominaria ainda a percepção de problemas, sobretudo quanto a custos relativos a entregas JIT.

\section{Metodologia}

Esta pesquisa envolveu estudos de casos na indústria automobilística brasileira, abordando três montadoras de automóveis ${ }^{(2)}$ e nove fornecedores de autopeças de 
primeiro escalão considerados como detentores de qualidade por seus clientes. Os dados foram obtidos em entrevistas pessoais com executivos das empresas. Nas montadoras ouviu-se um total de 11 respondentes, nas áreas de compras, logística e engenharia de produto. Nos fornecedores, o total de executivos entrevistados foi de 19 ( 9 dirigentes máximos, 3 diretores, 1 superintendente, 3 gerentes e 3 engenheiros). As empresas entrevistadas eram produtoras de freios; forjados e fundidos; produtos de estamparia (2); retentores, juntas e mangueiras; filtros; rodas; sistemas elétricos e bancos, estando situadas em Minas Gerais (2) e São Paulo (7).

Considerou-se que no estado atual das pesquisas das relações de fornecimento no Brasil a pesquisa deveria focar uma compreensão mais aprofundada do fenômeno, sendo a metodologia de estudos de caso a mais adequada. Esta escolha implica uma limitação em termos da generalização das conclusões para outras empresas.

\section{Resultados}

Conforme prevê a literatura, efetivamente há, pelo lado das montadoras, maior ênfase nos benefícios do que nos problemas decorrentes de mudanças nas relações e práticas de fornecimento. O Quadro 2 apresenta os benefícios citados no decorrer das entrevistas com as montadoras.

\section{Quadro 2: Benefícios Percebidos pelas Montadoras com os Novos Relacionamentos}

\begin{tabular}{|l|c|c|c|}
\hline \multirow{2}{*}{ Benefício Citado } & \multicolumn{2}{|c|}{ Montadora } \\
\cline { 2 - 4 } & A & B & C \\
\hline . Aumento de capacidade produtiva & & & \\
\hline . Ausência de paradas por falta de peças e componentes e poucos atrasos & & & \\
\cline { 2 - 3 } . Melhorias no fornecimento & & & \\
\hline Redução no custo de transporte pela proximidade dos fornecedores & & & \\
\hline . Maior flexibilidade de mix pela proximidade dos fornecedores & & & \\
\hline . Aumento no giro e redução nos custos de estoques & & & \\
\hline Melhoria de qualidade, levando a menores custos internos & & & \\
\hline & & & \\
\hline Melhoria de qualidade, levando a melhoria no produto & & & \\
\hline Alguma melhoria na qualidade dos materiais recebidos & & & \\
\hline Redução nos custos indiretos & & & \\
\hline Maior velocidade no desenvolvimento de novos produtos & & & \\
\hline . Melhor clima e perspectivas no relacionamento com os fornecedores & & & \\
\hline Redução na burocracia & & & \\
\hline Melhor comunicação com os fornecedores & & \\
\hline
\end{tabular}


A montadora $\mathrm{A}$, que enumerou o maior número de benefícios, era a que estava mais adiantada nas práticas de fornecimento nos moldes da produção enxuta. Os benefícios apontados por esta montadora coincidem com os indicados na literatura: ausência de interrupções na produção, menor número de atrasos, redução de diversos tipos de custos, entre os quais de transporte, manutenção de estoques, qualidade e indiretos. Algumas destas vantagens, como o aumento no giro e redução no custo com estoques, também estavam presentes nas outras montadoras.

É interessante observar que tanto para a montadora A quanto para a montadora $\mathrm{B}$ aparece como uma das vantagens das novas práticas a maior rapidez no desenvolvimento de novos produtos e sua colocação no mercado; ou seja, as duas montadoras que envolveram fornecedores locais em projeto tiveram resultados compensadores.

Houve também relato de problemas entre as montadoras, embora menos lembrados que os benefícios. O quadro a seguir sintetiza os problemas percebidos pelas montadoras nos novos padrões de relacionamento.

\section{Quadro 3: Problemas Percebidos pelas Montadoras com os Novos Relacionamentos}

\begin{tabular}{|l|c|c|c|}
\hline \multirow{2}{*}{ Problema Citado } & \multicolumn{3}{|c|}{ Montadora } \\
\cline { 2 - 4 } & $\mathrm{A}$ & $\mathrm{B}$ & $\mathrm{C}$ \\
\hline . Aumento da dependência mútua & & & \\
\hline Resistência de fornecedores a rebaixamento de escalão & & & \\
\hline . Resistência dos compradores a operações globalizadas & & & \\
\hline $\begin{array}{l}\text { Problemas de entregas atrasadas por problemas de comunicação com } \\
\text { fornecedores }\end{array}$ & & & \\
\hline . Custos adicionais para solucionar problemas nas entregas & & & \\
\hline . Necessidade de apoio a fornecedores em dificuldades & & & \\
\hline Menor economia de custos do que a esperada & & & \\
\hline
\end{tabular}

O aumento na dependência mútua, desvantagem mais usualmente encontrada na literatura, só foi apontado por A, talvez por seu maior avanço na direção de práticas enxutas, que eliminam as proteções através de fornecedores múltiplos ou estoques acumulados na cadeia de fornecimento. No caso de B não houve menção de qualquer problema percebido; já C ressentia-se, basicamente, de problemas na implantação de um sistema de entregas mais freqüentes, talvez típicos de uma fase de transição.

No caso dos fornecedores entrevistados, de modo geral, havia percepção posi- 
tiva das mudanças para um relacionamento mais exigente e integrado com suas clientes montadoras. Não houve, como no caso das montadoras, o registro de benefícios específicos de desempenho - em custo ou qualidade, por exemplo - mas comentários mais gerais sobre o efeito benéfico das novas práticas em termos de suas capacitações ou da cadeia de fornecimento.

Um fornecedor ressaltou ver mais benefícios do que problemas, à medida que também sua empresa estava ficando enxuta, diminuindo o seu número de fornecedores. Outros apontaram vantagens de ganhos de conhecimento, por estarem mais ligados à montadora e à engenharia do produto final. Um fornecedor destacou como benefício o fato de ficarem mais próximos dos clientes, facilitando a comunicação.

Resumindo a visão geral no grupo de nove empresas pesquisadas, um fornecedor colocou que a mudança havia sido dolorosa mas positiva, deixando sua empresa mais ágil e amadurecida; é interessante seu adendo, observando que, caso a pergunta houvesse sido colocada três anos antes, a resposta teria sido muito diferente. Isto certamente tem que ver com a característica de primeiro nível e o porte das empresas estudadas, à medida que, conforme observaram enfaticamente dois fornecedores, este seria o tipo de empresa que poderia beneficiar-se mais com as mudanças nos padrões de relacionamento. Nas palavras de um deles: "Quanto mais organizada for a empresa fornecedora, mais vantagem terá com as exigências". Ou seja, há vantagens, mas para quem puder acompanhar os movimentos e investimentos de uma indústria enxuta e globalizada.

Espelhando a visão de benefícios com as novas práticas, não houve percepção mais vasta de problemas nos novos relacionamentos. Um dos entrevistados chegou a colocar que "quem não quer problemas fica em casa", enquanto outro afirmou que "só as vítimas têm problemas".

Entre os problemas mais lembrados estão porém as freqüentes mudanças de mix por parte das montadoras, que comprometeriam em demasiado as entregas justin-time e causariam custos adicionais. $\mathrm{E}$, ainda, a dificuldade dos clientes em entender especificidades de entregas JIT, tomando atitudes prejudiciais à operação ou retardando decisões inadiáveis. A proximidade física também traria alguns problemas, aos olhos de um fornecedor, à medida que a montadora estaria pedindo mais do que deveria. Seriam, portanto, problemas mais de cunho operacional do que relacional.

Embora não chegassem a ser vistos como verdadeiros problemas, foram lembrados os custos causados pelo atendimento a diferentes sistemas de qualidade $\mathrm{e}$ de comunicação, bem como a necessidade de se contar com mão-de-obra muito capacitada e com muito profissionalismo. 
$\mathrm{Na}$ visão de um dos fornecedores, o grande problema estaria em escolher o parceiro errado; mas, ainda assim, seria algo que afetaria antes as montadoras do que os fornecedores.

É interessante observar a ausência de reclamações quanto a custos de estoques, mesmo entre aqueles fornecedores que, por problemas de suas operações internas, ainda os estavam assumindo para as montadoras. Isto seria visto antes como problema que lhes caberia resolver e não um ônus do sistema. Tampouco a maior dependência foi identificada como problema para os fornecedores, indicando talvez a percepção de que esta seria uma característica inerente ao novo sistema.

\section{CONCLUSÓES}

É possível que o pouco tempo de implementação das novas práticas de fornecimento na indústria automobilística brasileira não permita uma percepção perfeitamente definida de benefícios e problemas decorrentes. Constata-se, porém, que os benefícios e problemas averiguados pela pesquisa brasileira coincidem, em linhas gerais, com os mencionados na literatura. Além disso, confirmam-se no caso desta pesquisa as indicações da literatura no sentido de que as montadoras percebem maiores benefícios que os fornecedores, sendo tais vantagens mais específicas e relativas a desempenho.

O curto período de adoção das práticas enxutas, confrontado ao registro de benefícios de desempenho pelas montadoras instaladas no país, corrobora a possibilidade prevista na literatura de que as montadoras poderiam auferir vantagens com os novos relacionamentos já a curto prazo. Mais para trás na cadeia, porém, seria necessário um tempo maior na efetivação dos ajustes necessários para atender sem problemas (tais como custos adicionais) as exigências das montadoras. Isto se aplica mesmo a fornecedores como os entrevistados, todos reconhecidamente de elevada capacitação.

É interessante, no entanto, observar que ao contrário da literatura, que identifica inúmeros problemas percebidos pelos fornecedores em conseqüência da aplicação de práticas enxutas, a tônica entre os entrevistados, pertencentes ao primeiro escalão do parque produtor de autopeças no país, era a de que os novos relacionamentos conferiam-lhes vantagens. Estas seriam, em primeiro lugar, competitivas, à medida que, por serem empresas competentes, estariam em melhores condições do que outras no mercado local para atender às maiores exigências das montadoras. Além disso, os fornecedores estavam reconhecendo ganhos de conhecimento no contato maior com as montadoras e com a experiência em projetos 
conjuntos de desenvolvimento de produto. Mesmo aqueles que arcavam com custos de estoques, por ainda não estarem enxutos, consideravam que isto seria problema seu e não ônus do novo modelo, indicando percepção mais sistêmica das vantagens deste último. Seria, de fato, uma situação em que todos estariam ganhando, mesmo que as montadoras estivessem, como aliás sempre foi e provavelmente será na indústria, ganhando mais.

Apesar da adoção tardia da produção enxuta no país, parece efetivamente ter ocorrido uma mudança de paradigma, no sentido de que mudou a maneira de se olharem as operações de fornecimento, pelo menos no setor pesquisado. A atitude positiva dos fornecedores locais pode ser vista de fato como estímulo a um maior desenvolvimento do modelo de parceria na indústria automobilística brasileira. Futuros estudos, com maior número de fornecedores, poderão talvez confirmar as indicações aqui obtidas quanto à existência de mais benefícios do que problemas na prática do fornecimento enxuto.

\section{Notas}

1 Muitas das vantagens para os fornecedores nesta abordagem depende da adoção por estes de práticas JIT também em suas operações internas.

2 A pesquisa envolveu, de fato, as quatro montadoras de automóveis instaladas no país em 1995. Para os efeitos do presente trabalho, porém, somente três foram consideradas; a quarta passava por grande e recente reestruturação de suas operações brasileiras, não sendo possível, por isso, identificar benefícios ou problemas.

\section{RefERÊNCIAS BibLIOGRÁFICAS}

ANFAVEA.

Anuário estatístico da indústria brasileira. 1996.

ARKADER, R.

Relações de fornecimento no contexto da produção enxuta : um estudo na Indústria Automobilística Brasileira. Rio de Janeiro, 1997. Tese (Doutorado em Administração) - Instituto de PósGraduação e Pesquisa em Administração, Universidade Federal do Rio de Janeiro. 
BILLESBACH, T. J.;

HARRISON, A.;

CROOM-MORGAN, S.

Supplier performance measures and practices in JIT companies in the US and the UK. International Journal of Purchasing and Materials Management, p. 2428, Fall 1991.

CARLYSLE, J. A.;

PARKER, R. C.

Beyond negotiation : redeeming customer-supplier relationships. New York : John Wiley \& Sons, 1989.

\section{CUSUMANO, M. A.}

Manufacturing innovation : lessons from the Japanese auto industry. Sloan Management Review, p. 29-39, Fall 1988.

CUSUMANO, M. A.;

TAKEISHI, A.

Supplier relations and management : a survey of Japanese, Japanese-transplant, and U.S. auto plants. Strategic Management Journal, v. 12, p. 563-588, 1991.

DELBRIDGE, R.;

OLIVER, N.

Narrowing the gap? Stock turns in the Japanese and Western car industries. International Journal of Production Research, v. 29, n. 10, p. 2083-2095, 1991.
DION, P. A. et al.

JIT implementation : a growth opportunity for purchasing. International Journal of Purchasing and Materials Management, p. 32-38, Fall 1992.

FAWCETT, S. E.;

BIROU, L. M.

Just-in-time sourcing techniques : current state of adoption and performance benefits. Production and Inventory Management Journal, p. 08-24, First Quarter 1993.

FLEURY, P. F.;

ARKADER, R.

On the way to buyer-supplier partnership practices : a study in the Brazilian automobile assembly industry. In: $\quad 3 R D$ I N T E R N A T I O N A L CONFERENCE OF THE EUROPEAN OPERATIONS $M$ A $N$ A G E M E N T ASSOCIATION (1996: London). Proceedings... London : EurOMA, 1996. p. 231-236.

HELPER, S.

How much has really changed between U.S. automakers and their suppliers? Sloan Management Review, p. 15-28, Summer 1991.

Three step forward, two steps back in automotive supplier relations. Technovation, v. 14, n. 10, p. 01-08, 1994. 
HELPER, S.;

SAKO, M.

Supplier relations in the auto industry in Japan and the USA : are they converging? Sloan Management Review, p. 77-84, Spring 1995.

\section{HINES, P.}

Creating world class suppliers : unlocking mutual competitive advantage. London : Pitman, 1994.

KARLSSON, C.;

NORR, C.

Total effectiveness in a just-in-time system. International Journal of Operations \& Production Management, v. 14, n.3, p. 4665, 1994.

LAMMING, R.

Beyond partnership : strategies for innovation and lean supply. Englewood Cliffs, NJ : Prentice Hall, 1993.

LEAVY, B.

Two strategic perspectives on the buyer-supplier relationship. Production and Inventory Management Journal, p. 47-51, 2nd Quarter 1994.

LYONS, T. F.; KRACHENBERG, A. R.; HENKE JR., J. W.

Mixed motive marriages : what's next for buyer-supplier relations? Sloan Management Review, p. 29-36, Spring 1990.
NEW, S.

Boundary strategies : case studies in purchasing and the operational limits of the organisation. European Operations Management Association, June 1994.

NISHIGUSHI, T.

Strategic dualism : an alternative in industrial societies. Oxford, 1988. Thesis (PhD).

O'NEAL, C. R.

The buyer-seller linkage in a justin-time environment. Journal of Purchasing and Materials Management, p. 34-40, 1989.

PURDY, L.; ASTAD, U.; SAFAYENI, F.

Perceived effectiveness of the automotive supplier evaluation process. International Journal of Operations \& Production Management, v. 14, n. 6, p. 91100, 1994.

SAKO, M.

Prices, quality and trust : interfirm relations in Britain \& Japan. Cambridge : Cambridge University Press, 1992.

SAKO, M.;

LAMMING, R.; HELPER, S. R.

Supplier relations in the UK car industry : good news-bad news. European Journal of Purchasing \& Supply Management, v. 1, n. 4, p. 237-248, 1995. 
SCHONBERGER, R. J.;

GILBERT, J. P.

Just-in-time purchasing : a challenge for U.S. industry.

California Management Review, v. 36, n. 1, p. 54-68, Fall 1983.

SPENCER, M. S.;

ROGERS, D. S.;

DAUGHERTY, P. J.

JIT systems and external logistics suppliers. International Journal of Operations \& Production Management, v. 14, n. 6, p. 6074, 1994.

STUART, F. I.

Supplier partnerships : influencing factors and strategic benefits.
International Journal of Purchasing and Materials Management, p. 22-28, Fall 1993.

TURNBULL, P. et al.

Winners and losers - the 'tiering' of component suppliers in the UK automotive industry. Journal of General Management, v. 19, n. 1, p. 48-63, Autumn 1993.

WOMACK, J. P.; JONES, D. T.; ROOS, D.

The machine that changed the world. New York : Harper Perennial, 1991. 